\title{
An experimental test of the intermediate disturbance hypothesis using cultures of marine phytoplankton
}

\author{
Ulrich Sommer \\ Institut für Meereskunde, Düsternbrooker Weg 20, D-24105 Kiel. Germany
}

\begin{abstract}
Connell's intermediate disturbance hypothesis (IDH) predicts that species richness and diversity within a community are maximal at intermediate frequencies and intensities of disturbances. The predictions of the IDH were tested experimentally by semicontinuous multispecies cultures of marine phytoplankton. Disturbances consisted of dilutions at fixed intervals. The disturbances eliminated parts of the experimental populations but supplied fresh nutrients. Intervals between disturbances ranged from 1 to $14 \mathrm{~d}$. The magnitude of dilutions ranged from 30 to $99 \%$ removal. The IDH was fully supported when the results were expressed as species numbers or as Shannon's diversity index bascd on biomass. On the other hand, the IDH was only partially supported when the results were expressed as Shannon's diversity index based on cell numbers.
\end{abstract}

The causal explanation of species richness is one of the central issues of community ecology. Researchers have been intrigued by the contradiction between the competitive exclusion principle and the high diversity in apparently stable environments. Planktologists were made aware of that problem by Hutchinson's (1961) "paradox of the plankton." The theoretical nonequilibrium approaches to the solution of Hutchinson's paradox (Richerson et al. 1970; Grenney 1973; Ebenhöh 1988; Grover 1990) showed that periodic disturbances (i.e. changes of the external conditions of competition) could enhance the number of coexisting species. This prediction was confirmed experimentally with phytoplankton cultures (Sommer 1984, 1985; Grover 1991).

Ecologists working with larger organisms than plankton are usually more familiar with Connell's (1978) intermediate disturbance hypothesis (IDH) than with Hutchinson's paradox. An additional prediction is contained in the IDH: a decline of species richness under disturbances that are too intense. Recently, a rising interest among phytoplankton ecologists resulted in a symposium (Padisak et al. 1993) during which diversity-disturbance relationships in natural phytoplankton communities from lakes and rivers were analyzed. Experimental tests of the IDH have been rare (Robinson and Sandgren 1983; Gaedeke and Sommer 1986) and have not yet tried to disentangle the two components, disturbance frequency and disturbance intensity.

\section{Theory}

Connell's intermediate disturbance hypothesis predicts three unimodal relationships between species richness and disturbances: Species richness should be maximal at intermediate intensities of disturbance, at intermediate frequencies of disturbances, and after an intermediate span of time has elapsed after the last major disturbance. A disturbance is usually considered to be an event having a negative and a positive aspect. The "negative" aspect is the complete or partial destruction of populations. The "positive" aspect is an increase in availability of exploited resources. The unimodal shape of the diversity-disturbance relationship is caused by two factors that depress the species number at the near and far ends of the disturbance gradients: competitive exclusion following resource depletion reduces the number of coexisting species under undisturbed or nearly undisturbed conditions, and extinction of populations by strong disturbances occurs because only a few rapidly growing populations will be able to recover sufficiently fast from a massive reduction.

My study is focused on the long-term impact of disturbance intensity and disturbance frequency. It does not explore the third aspect of Connell's hypothesis - the timecourse of diversity after a disturbance (or between two disturbances). The hypothesized combined impact of disturbance frequency and disturbance intensity on diversity is illustrated in Fig. 1. A combination of frequent but weak disturbances (upper left corner of the quadratic diagram) is similar to an undisturbed steady state. Small disturbances will lead to short-term fluctuations in physiological rates that can be integrated within the lifespan of the organisms. The combination of rare but strong disturbances (lower right corner) will lead to the extinction of populations that cannot recover within the interval between disturbances. If disturbances are strong and frequent (upper right corner) no population will be able to recover. Rare and weak disturbances (lower left corner) will be inconsequential and similar to an undisturbed steady state. If these considerations are correct, only the diagonal from frequent and weak to rare and strong disturbances seems interesting. The experimental design of Robinson and Sandgren (1983) and of Gaedeke and Sommer (1986) was based on an inverse relationship between frequency and intensity of disturbances. In this study, I wanted to check this rationale; I therefore conducted experiments with constant disturbance intensities but variable intervals in addition to the "diagonal" design.

It has become common practice (cf. in most of the studies cited above) to replace the species number by the diversity index. The main problem of such usage arises from the conceptual weakness of "diversity" (Hurlbert 1971). In principle, theories about coexistence and competitive exclusion make predictions about species num- 

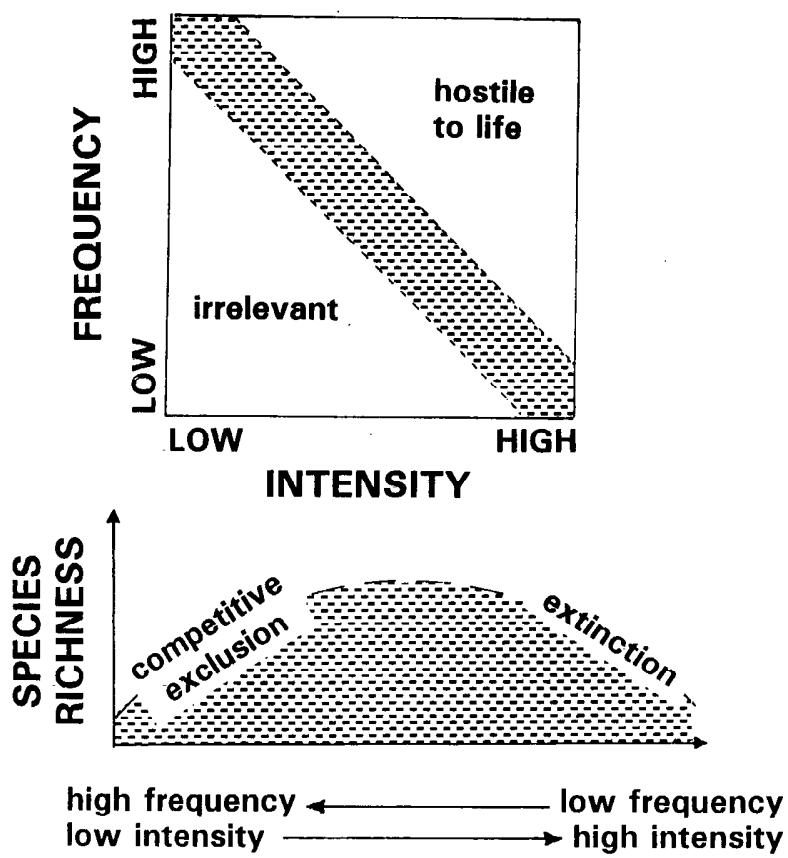

\section{DISTURBANCE}

Fig. 1. Diagrammatic representation of the intermediate disturbance hypothesis.

bers but not about diversity indices. A two-species equilibrium can be a one-sided mixture of $90: 10$ as well as an equitable mixture of $50: 50$. Diversity indices are used because they stabilize mathematically after accounting for the most common species, and no judgment is needed about whether rare species will eventually become extinct. However, diversity indices are always a combined measure of species richness and equitability (Washington 1984) and therefore the incorrect response variable if cocxistence of species is to be measured. Here, I use the diversity index only for the sake of compatibility with the literature. The valid test of the IDH, however, lies in the species number.

\section{Methods}

Experimental design-The experiments consisted of 100$\mathrm{ml}$ cultures of marine phytoplankton. The nature of disturbances was a discontinuous dilution with fresh medium at fixed intervals. Such a dilution has some analogy to episodic mixing events, which import nutrient-rich but plankton-poor water from deeper zones into the euphotic zone. The magnitude of dilution was constant (30\%) in the baseline experiments and inversely related to the frequency of dilutions in the diagonal experiments (Table 1). In the diagonal experiments, dilutions were adjusted to assure that the same time-averaged instantaneous growth rate (critical growth rate, $\mu_{\text {crit }}$ ) was needed to overcome the loss caused by the dilution. Notc that this rate is not identical to the death rate $(d)$ caused by dilution because dilutions were singular events while growth was a continuous, exponential process. They were calculated as
Table 1. Time interval between dilutions $(\Delta t$, in $\mathrm{d})$, magnitude of dilution $\left(D, V_{\text {new }} / V_{\text {tot }}\right)$, and critical growth rate $\left(\mu_{\text {crit }}\right.$, in ln-units $\mathrm{d}^{-1}$ ) in the bascline and diagonal design experiments.

\begin{tabular}{lllclc}
\hline \hline & \multicolumn{5}{c}{ Baseline } \\
$\Delta t$ & 1 & 2 & 3.5 & 7 & 14 \\
$D$ & 0.30 & 0.30 & 0.30 & 0.30 & 0.30 \\
$\mu_{\text {crit }}$ & 0.36 & 0.18 & 0.10 & 0.051 & 0.026 \\
& & & Diagonal & & \\
$\Delta t$ & 1 & 2 & 3.5 & 7 & 14 \\
$D$ & 0.30 & 0.51 & 0.71 & 0.92 & 0.993 \\
$\mu_{\text {crit }}$ & 0.36 & 0.36 & 0.36 & 0.36 & 0.36 \\
\hline
\end{tabular}

$$
d=\left(V_{\text {new }} / V_{\text {tot }}\right) / \Delta t ; \quad \mu_{\text {crit }}=-\ln \left(1-V_{\text {new }} / V_{\text {tot }}\right) / \Delta t .
$$

$V_{\text {new }}$ is the volume of fresh medium at each dilution event, $V_{\text {tot }}$ the total culture volume, and $\Delta t$ the time interval between dilutions. This implies that $\mu_{\text {crit }}$ decreases with $\Delta t$ in the baseline experiments.

Organisms-Both types of experiments were run twice, once with an inoculum composed of laboratory strains of marine phytoplankton and once with natural phytoplankton sampled from the Jade Bight (southern North Sea) on 24 May during the decline phase of the spring bloom. The laboratory inoculum consisted of 13 species, the natural inoculum contained 24 detectable species of phytoplankton plus some unicellular zooplankton. In both inocula most species were diatoms; Table 2).

Physical and chemical conditions-Cultures were maintained in 250-ml Erlenmeyer flasks and kept in suspension on a rotating shaking tablc. Cultures were shaken gently $(30 \mathrm{rpm})$ for $5 \mathrm{~min}$ each half hour in order to minimize detrimental effects of shaking. The experimental temperature was $15^{\circ} \mathrm{C}$. Light was supplied by a combination of white (Osram Biolux) and purple (Osram Fluora) fluorescent tubes. The light intensity measured in flasks containing medium but no algae was $\sim 200 \mu \mathrm{mol}$ quanta $\mathrm{m}^{-2} \mathrm{~s}^{-1}$. Thus, light limitation, even of algae with high requirements, was precluded. The L/D periodicity was $16: 10$ to mimic early summer conditions.

The medium was an artificial seawater medium with nutrient, trace element, and vitamin additions similar to the f/2 medium of Guillard and Ryther (1972). Si, N, and $P$, however, were modified: $50 \mu \mathrm{mol}$ liter $^{-1}$ silicate; 10 $\mu$ mol liter ${ }^{-1}$ nitrate (no ammonium); $2 \mu \mathrm{mol} \mathrm{liter}^{-1}$ phosphate. The $N: P$ ratio of $5: 1$ was chosen to preclude $P$ limitation, while the $\mathrm{Si}: \mathrm{N}$ ratio of $5: 1$ implied $\mathrm{N}$ limitation of most species and Si limitation of some diatoms with high Si requirements.

Sampling and counting-Samples for cell counts were taken twice per week and fixed with Lugol's iodine solution. When the sampling date coincided with the dilution date, the sample was taken from the undiluted culture. Cells were counted according to the Utermöhl inverted microscope technique. For large species (mean cell volume, $>50,000 \mu \mathrm{m}^{3}$ ), the entire counting chamber was screened. Medium-sized species (cell volume, 1,000- 
Table 2. List of phytoplankton species; abbreviation in figures (1), absence or presence in the laboratory (2) and in the natural (3) inoculum, and mean cell volume ( $V$, in $\left.\mu \mathrm{m}^{3}\right)$

\begin{tabular}{|c|c|c|c|c|}
\hline & 1 & 2 & 3 & $V$ \\
\hline \multicolumn{5}{|l|}{ Centric diatoms } \\
\hline Biddulphia aurita var. minima & BIDD & - & + & 10,000 \\
\hline Biddulphia regia & & - & + & 200,000 \\
\hline Biddulphia sinensis & & - & + & 200,000 \\
\hline Chaetoceros socialis & . & + & - & 280 \\
\hline Chaetoceros sp. & & - & + & 700 \\
\hline Cóscinodiscus wailesii & COSC & + & + & 600,000 \\
\hline Ditylum brightwellii & DITY & + & + & 120,000 \\
\hline Eucampia zodiacus & EUCA & + & - & 16,000 \\
\hline Rhizosolenia fragilissima & & - & + & 80,000 \\
\hline Rhizosolenia setigera & RHIZ & - & + & 60,000 \\
\hline Skeletonema costatum & SKEL & + & + & 250 \\
\hline Stephanopyxis turris & & + & - & 60,000 \\
\hline Thalassiosira levanderi & & - & + & 700 \\
\hline Thalassiosira punctigera & & - & + & 65,000 \\
\hline Thalassiosira rotula & THAL & + & - & 9,900 \\
\hline Thalassiosira sp. $(12 \mu \mathrm{m})$ & & - & + & 2,200 \\
\hline \multicolumn{5}{|l|}{ Pennate diatoms } \\
\hline Asterionella glacialis & ASTE & + & + & 170 \\
\hline Asterionella kariana & & - & + & 250 \\
\hline Nitzschia closterium & NITZ & + & + & 190 \\
\hline Nitzschia longissima & NILO & - & + & 250 \\
\hline Pseudonitzschia pungens & & + & - & 400 \\
\hline Thalassionema nitzschioides & & - & + & 300 \\
\hline \multicolumn{5}{|l|}{ Flagellates } \\
\hline Chrysochromulina polylepis & & + & + & 250 \\
\hline Dunaliella tertiolecta & & + & - & 180 \\
\hline Gymnodinium sp. & GYMN & - & + & 600 \\
\hline Pyramimonas sp. & & - & + & 120 \\
\hline Rhodomonas sp. & & + & + & 300 \\
\hline Unident. $5-\mu \mathrm{m}$ flag. & & - & + & 60 \\
\hline
\end{tabular}

$50,000 \mu \mathrm{m})$ were counted at a $200 \times$ magnification in randomly selected transects. Counting stopped after 400 cells were counted. Small cells were counted at a $400 \times$ magnification in randomly selected fields. Again, counting was stopped after 400 cells. Counting of 400 cells gives a $95 \%$ C.L. of $\pm 10 \%$ if cells are randomly distributed (Lund et al. 1958).

Biomass was estimated as cell volume. Cell volumes were calculated by appropriate geometric fomulae after microscopic measurements of at least 20 individuals of each species at the start and at the end of experiments. A uniform value for each species (Table 2) was used for calculations because differences between treatments and between the start and the end values were not significant $(P>0.05)$.

Measures of species richness and diversity-The species number $(S)$ contains all species detected by the counting procedure. Diversity was measured according to Shannon and Weaver (1949):

$$
H^{\prime}=-\Sigma p_{i} \ln p_{i}
$$

$p_{i}$ is the relative importance of species $i$, derived either from cell numbers $\left(N_{i} / N_{\text {tot }}\right)$ or from biomass $\left(B_{i} / B_{\text {tot }}\right)$. For the sake of brevity, the diversity index based on numbers will be called abundance diversity $\left(H N^{\prime}\right)$ and the diversity index based on cell volumes will be called biomass diversity $\left(H B^{\prime}\right)$.

\section{Results}

The time-course of the experiments (Fig. 2) was rather typical for multispecies competition cultures. Initially there was an abundance and biomass increase of all species that lasted for 7-10 d. The initial incrcasc suggested that later exclusions were due to biotic interactions and not to chemical or physical unsuitability of culture conditions. The benign character of the physical environment is further indicated by the fact that even Coscinodiscus became a persisting species in a number of treatments despite its notorious sensitivity (reviewer's comment) to shaking. Thereafter, the first species began to decline. After $\sim 2$ weeks, the first species were excluded. There was no experiment without species loss. At the end of the experiments (after 7 weeks), two to five species could still be detected. In the experiments with the laboratory inoculum, only diatoms persisted (Fig. 3). In the experiments with the natural inoculum, there were four cultures 


\section{DIAGONAL DESIGN \\ LAB-INOCULUM}
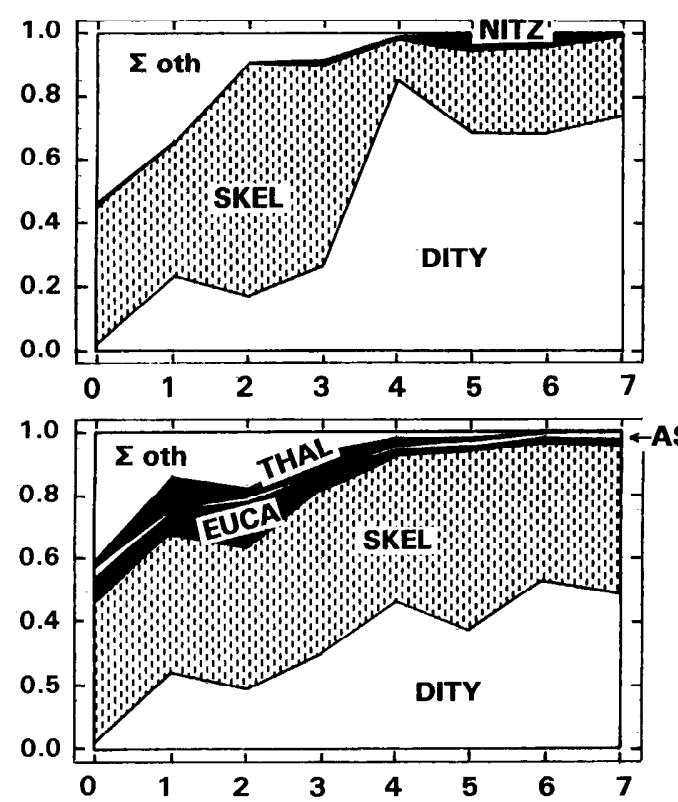

$3.5 \mathrm{~d}$
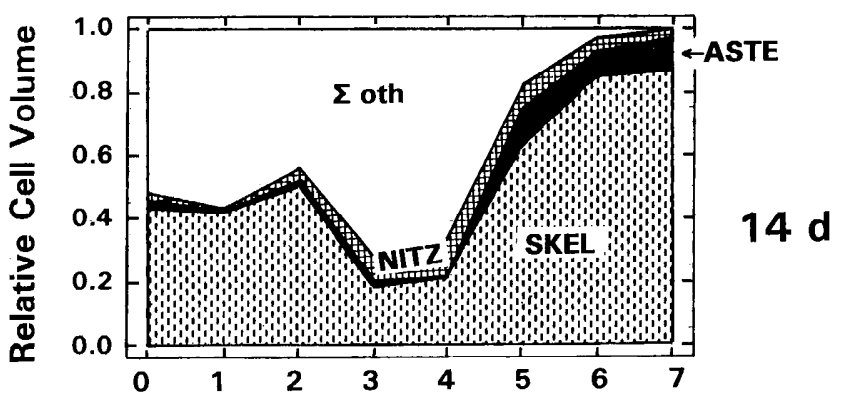

Time (weeks)

Fig. 2. Example for the time-course of experiments. Composition of biomass in the experiments with the diagonal design and the laboratory inoculum at disturbance intervals of $1,3.5$, and $14 \mathrm{~d}$. Species abbreviations given in Table 2.

with a subdominant but persisting dinoflagellate population. However, diatoms were always dominant by number and by biomass (Fig. 4).

Most of the protozoa disappeared from the cultures with the natural inoculum, except for a large athecate amoeba (four experiments: diagonal design, 2-d interval and baseline design, 1-, 3.5-, and 7-d intervals) and the heterotrophic dinoflagellate Protoperidinium bipes (three experiments: diagonal design, 2-d interval and baseline design, 7- and 14-d interval). In those experiments, the amoeba persisted at abundances between 8 and $15 \mathrm{ml}^{-1}$ and Protoperidium at abundances between 200 and 300 $\mathrm{ml}^{-1}$. The presence of the heterotrophs seemed to influence the species composition of algae, but it did not break the continuity of the species number trend along the gradient of disturbance intervals. The most notable effect of

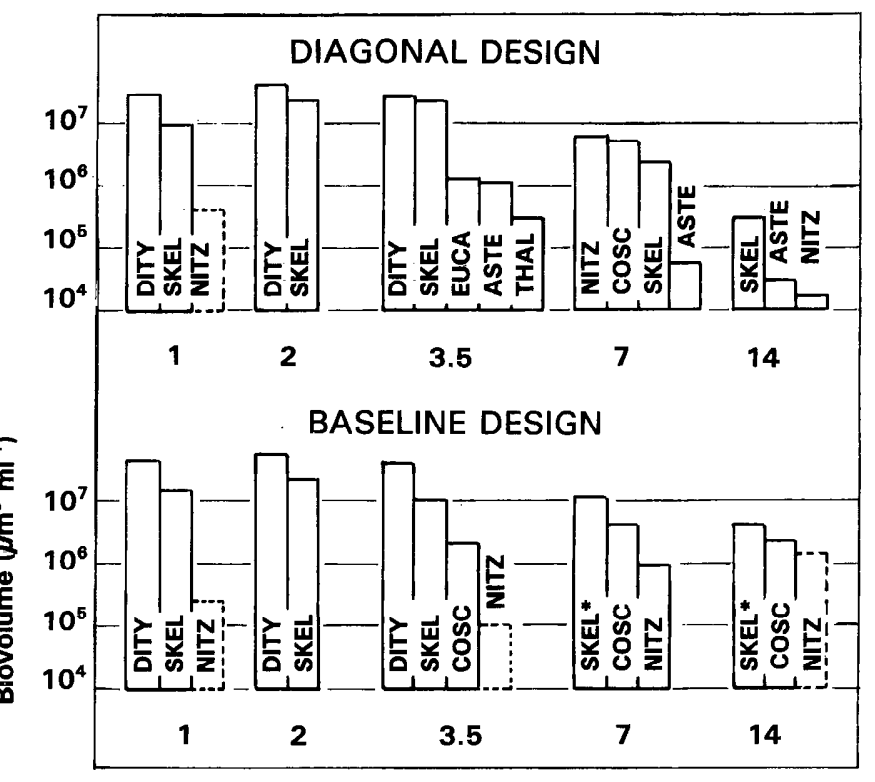

Disturbance Interval (d)

Fig. 3. Biovolume (log-scaled, in $\mu \mathrm{m}^{3} \mathrm{ml}^{-1}$ ) at the end of experiments with the laboratory inoculum. Broken columns: species classified as potentially excluded; $*$-colonies clumped. Species abbreviations given in Table 2 .

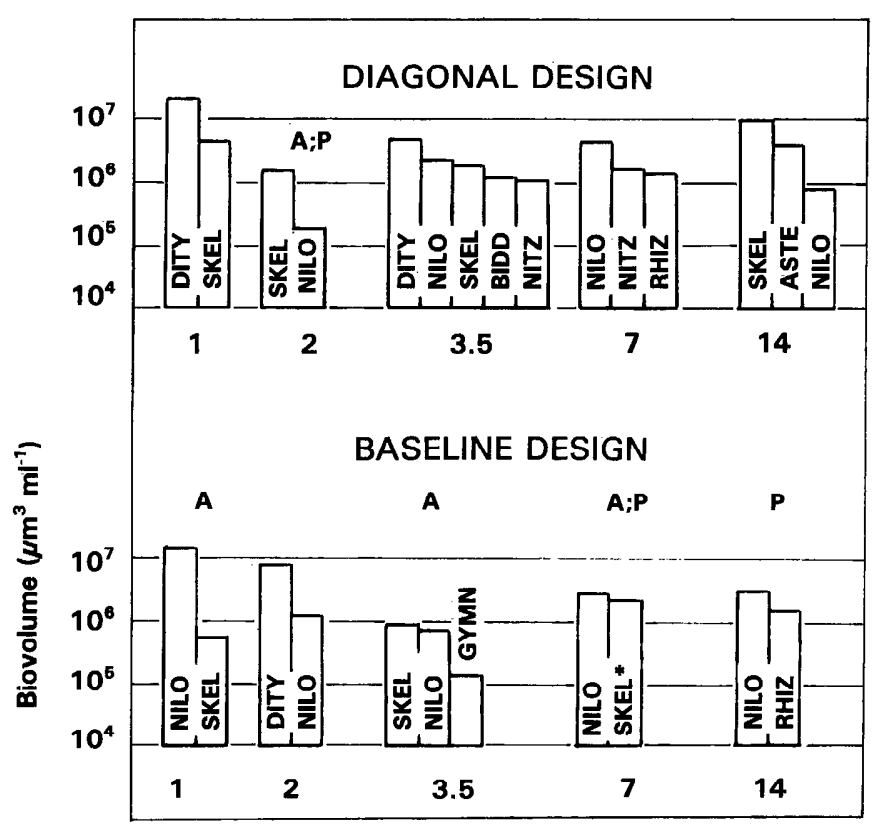

Disturbance Interval (d)

Fig. 4. As fig. 3, but with the natural inoculum. A-Amoeba present at the end of experiment; $\mathrm{P}$-Protoperidinium present at the end of experiment. 
LAB-INOCULUM

NAT-INOCULUM

after 7 weeks
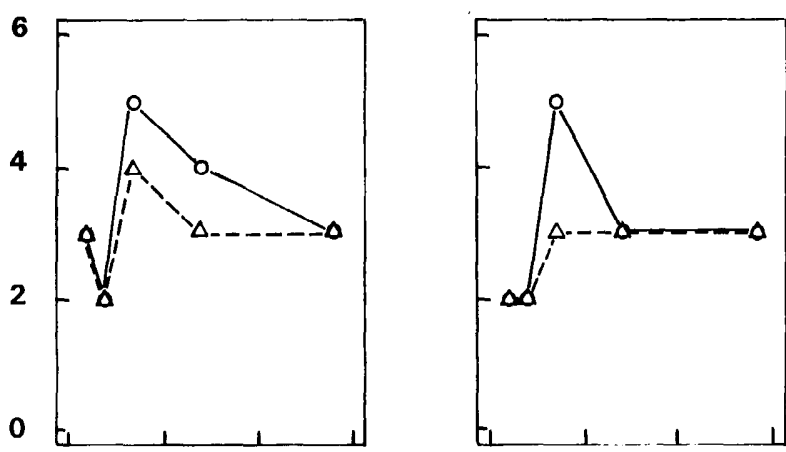

equilibrium

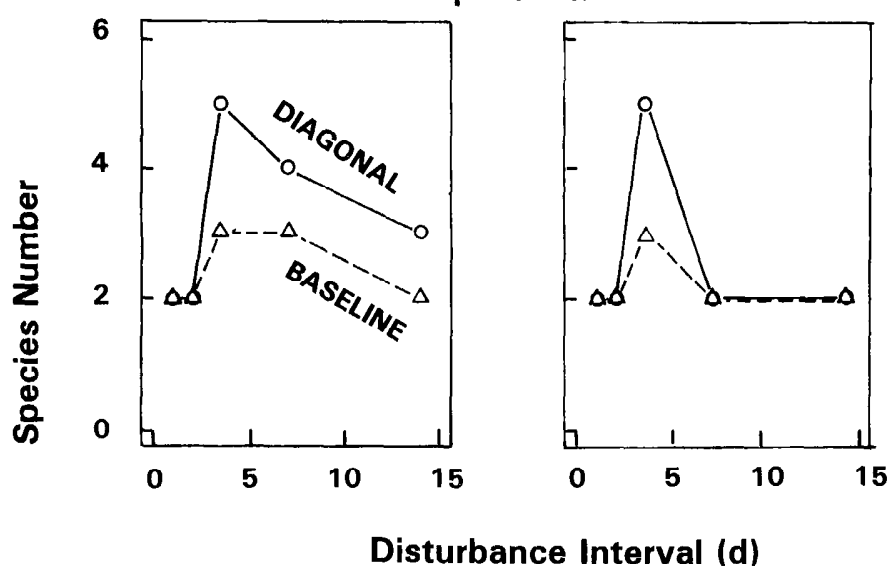

Fig. 5. Response of the species number $\left(S_{7}\right.$ and $\left.S_{e}\right)$ to the length of the disturbance intervals. Solid line-diagonal design; broken line-baseline design.

the amoeba was the exclusion of Ditylum brightwellii. This species was one of the dominant diatoms in the laboratory inoculum experiments with the same disturbance regime, except in the baseline experiment with 7-d intervals. It had also been successful in the frequently disturbed (interval, $<1$ week) natural inoculum experiments without amoebae.

\section{Discussion}

Species number-For the further discussion of results, I use two kinds of species numbers. $S_{7}$ is the raw species number, comprising all species detected by my counting method after 7 weeks. A few of the species detected at the end of experiments were still continuously declining, suggesting that they would have been excluded under prolonged cultivation (e.g. Nitzschia closterium in Fig. 2, top panel). This assumption was tested by a regression analysis of $\log N$ and of $\log p_{i}$ on time. If both regressions had a significantly negative slope $(P<0.05)$ the species was considered as potentially excluded (shown by a broken contour in the column diagrams of Fig. 3). $S_{e}$ is the
LAB-INOCULUM NAT-INOCULUM based on cell volumes
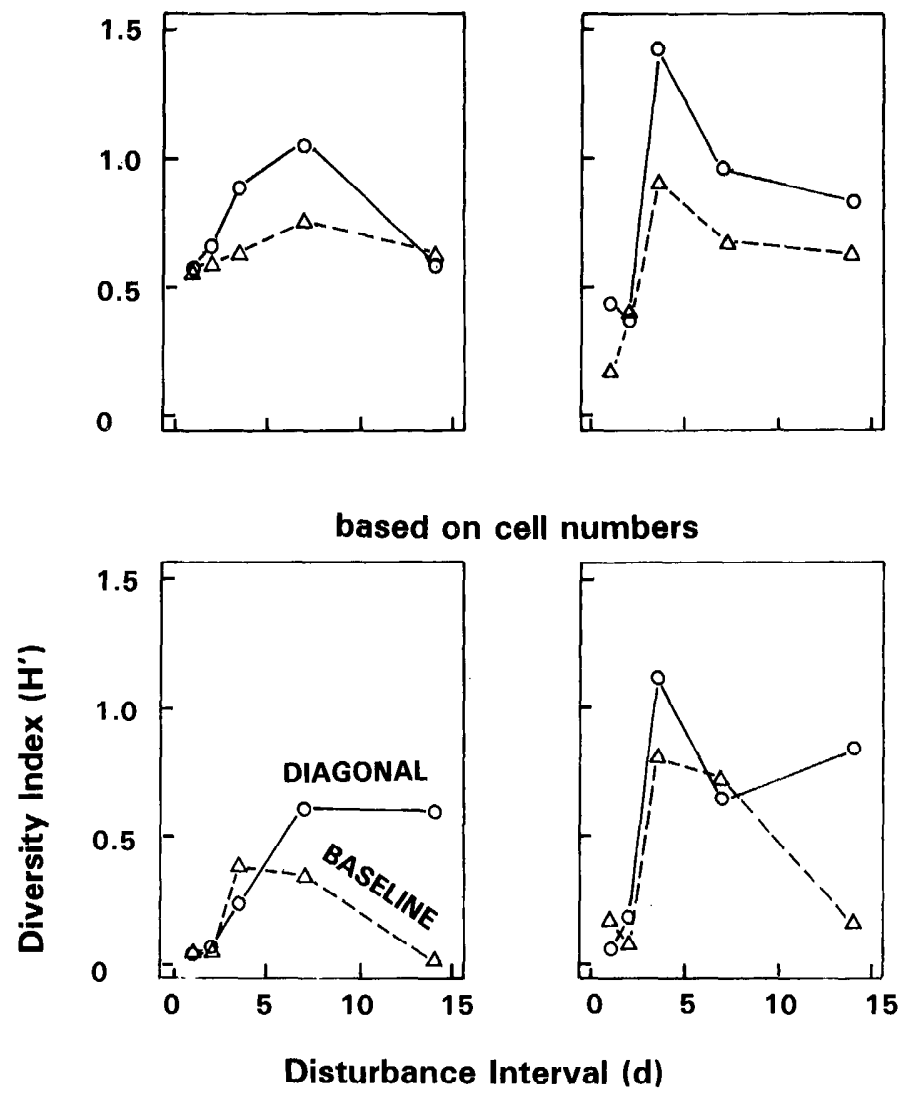

Fig. 6. Response of biomass diversity and of abundance diversity to the length of the disturbance interval. Solid linediagonal design; broken line-baseline design.

equilibrium species number defined by $S_{7}$ minus the number of potentially excluded species.

The difference between $S_{7}$ and $S_{e}$ was rather small (Fig. 5 ), and the trends were similar in both cases. Maximal species numbers $\left(S_{7}=5 ; S_{e}=5\right)$ were found at disturbance intervals of $3.5 \mathrm{~d}$ in the diagonal design experiments. This peak at intermediate disturbance intervals was absent (natural inoculum) or less pronounced (laboratory inoculum) in the baseline design experiments. The species number at 1- and 2-d intervals $\left(S_{h}\right)$ conforms to the theoretical expectations for undisturbed steady state competition with two limiting resources (Tilman 1982). This result is similar to the freshwater experiments of Gaedeke and Sommer (1986), where no increase of species numbers by periodic disturbances was observed when the dilution interval was less than one mean generation time.

Diversity-Similar to $S$, the diversity index could also be calculated either from all species present after 7 weeks or only from the species considered truly coexisting. However, the differences between the two were small $(<0.05$ units). $H^{\prime}$ calculated in the latter way is shown in Fig. 6 and used for the statistical analysis. 
Table 3. Multiple regression analysis (stepwise variable selection, backward procedure, $F$-to-remove $=4$ ) of species number $\left(S_{7}, S_{e}\right)$, biomass diversity $\left(H B^{\prime}\right)$, and abundance diversity $\left(H N^{\prime}\right)$ on interval length between dilutions $(I)$, magnitude of dilutions $(D)$, and initial species number $\left(S_{0}\right)$.

$$
\begin{aligned}
& S_{7}=1.21+0.22 I-0.015 I^{2}+8.24 D-5.58 D^{2}-0.06 S_{0}, \\
& r^{2}=0.44 ; P=0.116 \\
& S_{c}=-0.84+0.30 I-0.02 I^{2}+10.3 D-6.88 D^{2} \\
& r^{2}=0.58 ; P=0.0083 \\
& H B^{\prime}=-0.28+0.14 I-0.008 I^{2}+2.44 D-1.75 D^{2} \\
& r^{2}=0.52 ; P=0.0202 . \\
& I I N^{\prime}=-0.73+0.118 I-0.0076 I^{2}+0.64 D+0.028 S_{0} \\
& r^{2}=0.67 ; P=0.0014
\end{aligned}
$$

Biomass diversity exhibited qualitatively the same trend as species. numbers. The maximal values were found at an intermediate frequency in the experiments with the diagonal design. The diversity peak occurred at 7-d intervals in the experiments with the laboratory inoculum and at $3.5 \mathrm{~d}$ in the experiments with the natural inoculum. In the experiments with the baseline design, diversity showed only a weak unimodal response (laboratory inoculum) or it appeared to level off at intermediate interval lengths (natural inoculum).

The response of abundance diversity to the disturbance regime was quite different. There was a unimodal response in the experiments with the baseline design but not in the experiments with the diagonal design. In the latter, $H N^{\prime}$ increased with interval length at short intervals and leveled off at longer intervals.

Statistical analysis-The predictions of the IDH were tested by a multiple regression analysis with a stepwise variable selection (backward procedure, $F$-to-remove $=$ 4). The dependent variables were $S_{7}, S_{e}, H B^{\prime}$, and $H N^{\prime}$. The independent variables were the interval length $(I$, in d), $I^{2}$, the magnitude of dilutions $\left(D, V_{\text {new }} / V_{\text {tot }}\right), D^{2}$, and the inoculum species number $\left(S_{0}\right)$. According to the hypothesis, there should be a unimodal response to $I$ and $D$ (linear terms significantly positive, quadratic terms significantly negative). A significant response to $S_{0}$ would indicate a difference between the experiments with the natural inoculum and the experiments with the laboratory inoculum.

The regression equations in Table 3 permit the following conclusions: the difference between the inocula had no impact on the outcome of my experiments, except for the abundance diversity; the predictions of the IDH were confirmed when the species number was used as the response variable, although the regression slightly failed to become significant if $S_{7}$ was used; the predictions of the IDH were fully confirmed when biomass diversity was used as the response variable; and the predictions of the IDH were only partially confirmed when abundance diversity was used as the response variable. There was a unimodal response to the interval length but not to the strength of disturbances.

The support for the IDH does not imply that disturbances of appropriate intensity and frequency are the only mechanisms that explain the coexistence of species in plankton communities. The role of selective and temporally variable grazing and sedimentary losses in the maintenance of species richness needs further experimental exploration. It could be especially important that predator-prey systems can exhibit temporal variability without external disturbance by physical factors. Thus, external disturbance might lose its importance in counteracting competitive exclusion. Testing this possibility in an experimental system with several trophic levels would be the logical next step.

\section{References}

CONNELl, J. 1978. Diversity in tropical rainforests and coral reefs. Science 199: 1304-1310.

EBENHÖH, W. 1988. Coexistence of an unlimited number of algal species in a model system. Theor. Pop. Biol. 34: 130144.

Gaedeke, A., AND U. Sommer. 1986. The influence of the frequency of periodic disturbances on the maintenance of phytoplankton diversity. Oecologia 71: 25-28.

GRENNEY, W. J. 1973. A theoretical approach to interspecific compctition in the phytoplankton community. Am. Nat. 107: 405-425.

GROVER, J. P. 1990. Resource competition in a variable environment: Phytoplankton growing according to Monod's model. Am. Nat. 136: 772-789.

- 1991. Non-steady state dynamics of algal population growth: Experiments with two chlorophytes. J. Phycol. 27: 70-79.

Guillard, R. R. L., AND J. H. Ryther. 1962. Studics on marine diatoms. 1. Cyclotella nana Hustedt and Detonula confervacea Gran. Can. J. Microbiol. 8: 229-239.

HuRLBERT, S. H. 1971. The nonconcept of species diversity: A critique and alternative parameters. Ecology 52: 577586.

Hutchinson, G. E. 1961. The paradox of the plankton. Am. Nat. 95: $137-147$.

Lund, J. W., C. KIPLING, AND E. D. LeCren. 1958. The inverted microscope method of estimating algal numbers and statistical basis of estimations by counting. Hydrobiologia 11: $143-170$.

PAdisak, J., C. S. ReYNolds, AND U. SOMmer [eds.]. 1993. Intermediate disturbance hypothesis in phytoplankton ecology. Develop. Hydrobiol. 81. Kluwer.

Richerson, P., R. ARMSTrong, AND C. R. Goldman. 1970. Contemporaneous disequilibrium, a new hypothesis to ex- 
plain the "paradox of plankton." Proc. Natl. Acad. Sci. 67: 1710-1714.

Robinson, J. V., AND C. D. SANDGRen. 1983. The effect of temporal environmental heterogeneity on community structure: A replicated experimental study. Oecologia 57: 98-112.

ShanNon, C. E., AND W. WeAver. 1949. The mathematical theory of communication. Univ. Illinois.

SOMMER, U. 1984. The paradox of the plankton: Fluctuations of phosphorus availability maintain diversity in flowthrough cultures. Limnol. Oceanogr. 29: 633-636.

- 1985. Comparison between steady state and non-steady state competition: Experiments with natural phytoplankton. Limnol. Oceanogr. 30: 335-346.

Tilman, D. 1982. Resource competition and community structure. Princeton.

Washington, H. G. 1984. Diversity, biotic and similarity indices. Water Res. 18: 653-694.

Submitted: 16 September 1994 Accepted: 16 May 1995 Amended: 22 June 1995 